\title{
Investigating Entertainment and Learning in a Multi-User 3D Virtual Environment
}

\author{
Nicoletta Di Blas ${ }^{1}$, and Caterina Poggi ${ }^{2}$ \\ ${ }^{1}$ Politecnico di Milano, Italy, nicoletta.diblas@ polimi.it \\ ${ }^{2}$ University of Wisconsin at Madison, USA, cpoggi@wisc.edu
}

\begin{abstract}
How can we include entertainment into an ITC-based educational experience? Edutainment is the blending of education and entertainment; it is about engaging, enjoyable experiences providing a learning value. Understanding better how to make a pedagogical intervention engaging, to stimulate significant effort and reasoning from all kinds of students, could generate a positive impact on education. We analyze the entertaining features in the design of Learning@Europe (www.learningateurope.net), an edutainment experience on European history for high-school students, based on a shared 3D virtual world. L@E has involved since 2004 over 6,130 students (aged 14 to 19) from 18 European countries plus USA, with highly rewarding results in terms of engagement and learning.
\end{abstract}

Keywords: Entertainment, Learning, Games, 3D Worlds, Virtual Reality

\section{Introduction}

How can we effectively include elements of entertainment into a technology-based educational experience, turning it into successful edutainment? Edutainment is the blending of education and entertainment; it is about experiences that are engaging and enjoyable, while at the same time providing a learning value. Edutainment can be seen as incorporating educational value into a leisure activity, so that players incidentally learn while having fun; or as making an educational experience more engaging, so that users are more motivated to learn. The focus on entertainment or education entails very different scenarios: in the first case users play in their spare time, to have fun: any learning resulting from it represents an additional value, which must not stifle the engagement; when learning is the primary goal, instead, the activity may take place in formal educational environments, e.g. schools, with a more "captive" audience, and it must provide substantial educational value; entertaining features may motivate users, enhance their experience, and engage also those who usually resist involvement. 
This paper focuses on educational applications that are also fun to use. Gaining a better understanding of how to make a pedagogical intervention engaging, so as to stimulate significant effort, reasoning, and time on-task from all kinds of students, could generate a relevant - and highly needed - positive impact on education.

Many disciplines may contribute to the understanding of edutainment. In the first section we review relevant literature on game design, virtual reality for education, and motivationalist theories. Subsequent sections analyze the entertaining features in our edutainment programs based on shared 3D virtual worlds: we focus on Learning@Europe, an experience on European history for international highschool students which involved since 2004 over 6,130 students (aged 14 to 19) from 19 countries, with highly rewarding results both in terms of student engagement and educational benefits achieved. We describe the games and activities designed to make Learning@Europe engaging, and some evaluation results showing the elements that participants found most compelling. In the conclusions we summarize the critical elements that help creating engagement and learning in our programs and relate them to theory, drawing some general lessons.

\section{Related work}

This section presents theory and practice on the potential learning value of games.

Games are generating a growing interest in academic research as an emerging new media and design field. 70 years ago Huizinga (1938) recognized play as the root of many human activities: "Now in myth and ritual the great instinctive forces of civilized life have their origin: law and order, commerce and profit, craft and art, poetry, wisdom and science. All are rooted in the primeval soil of play".

First, we attempt to understand the nature of games.

\subsection{A Taxonomy of Fun}

What is a game? What makes games fun? Hunicke et al. (2004) proposed a taxonomy of fun, listing several game goals (Tab. 1). Caillois (1961) identified 4 major categories of games: AGON, based on competition (e.g. sports); ALEA, based on chance (e.g. gambling, dices); MIMESIS, based on role-playing of fantasy characters in imaginary settings; and ILINX, or dizziness, based on various states of mental frenzy (e.g. the roller-coaster). Bartle (1996) identified 4 reasons why people like playing MUDS (multi-user dungeons, or text-based online role-play games): Achievers like challenges and competition, Explorers are interested in the internal dynamics of the environment, Socializers take pleasure in social interaction, whereas Killers enjoy causing distress in other players. Koster (2004) identified several elements that produce pleasure, enjoyment, and possibly fun: stories, aesthetic appreciation, maneuvering to increase one's social status, flow, and visceral reactions. Finally, Prensky (2001) identified 11 reasons why 
games are engaging (shown in Tab. 1 or later in this article). Tab. 1 shows the overlapping of many elements identified by the various authors.

Table 1. A taxonomy of fun, according to different authors

\begin{tabular}{|c|c|c|c|c|}
\hline Hunicke et al. & Bartle & Callois & Koster & Prensky \\
\hline $\begin{array}{l}\text { Sensation. Game as } \\
\text { sense-pleasure. }\end{array}$ & & (ILINX) & $\begin{array}{c}\text { Aesthetic } \\
\text { appreciation }\end{array}$ & $\begin{array}{l}\text { Games are fun. That gives us } \\
\text { enjoyment and pleasure. }\end{array}$ \\
\hline $\begin{array}{c}\text { Fantasy. Game as } \\
\text { make-believe. } \\
\text { Narrative. Game as } \\
\text { drama. }\end{array}$ & & MIMESIS & Storytelling & $\begin{array}{c}\text { Games have representation } \\
\text { and story. That gives us } \\
\text { emotion. }\end{array}$ \\
\hline $\begin{array}{l}\text { Challenge. Game } \\
\text { as obstacle course. }\end{array}$ & $\begin{array}{l}\text { Achievers } \\
\text { (Killers) }\end{array}$ & AGON & $\begin{array}{l}\text { Fun }= \\
\text { mastering a } \\
\text { problem }\end{array}$ & $\begin{array}{c}\text { Games have competition and } \\
\text { challenge. That gives us } \\
\text { adrenaline. }\end{array}$ \\
\hline $\begin{array}{l}\text { Fellowship. } \\
\text { Game as social } \\
\text { framework. }\end{array}$ & Socializers & & $\begin{array}{c}\text { Social status } \\
\text { maneuvers }\end{array}$ & $\begin{array}{l}\text { Games have interaction. That } \\
\text { gives us social groups. }\end{array}$ \\
\hline $\begin{array}{l}\text { Discovery. Game as } \\
\text { uncharted territory. }\end{array}$ & Explorers & (ILINX) & $\begin{array}{l}\text { (Visceral } \\
\text { reactions) }\end{array}$ & \\
\hline $\begin{array}{l}\text { Expression. Game } \\
\text { as self-discovery. }\end{array}$ & (Killers) & MIMESIS & & \\
\hline $\begin{array}{c}\text { Submission. Game } \\
\text { as pastime }\end{array}$ & & & Flow & \\
\hline & & ALEA & & \\
\hline
\end{tabular}

Good games are intrinsically engaging: motivationalist theories may help understanding them. According to Csikszentmihalyi (1991), for example, people work at their best when they are in a state of intense concentration that he calls Flow, with one or more of the following characteristics: clear goals (expectations and rules are discernible); high degree of concentration focused on a limited field of attention (a person engaged in the activity can focus and delve deeply into it); loss of self-consciousness: merging of action and awareness; distorted sense of time - one's subjective experience of time is altered; direct and immediate feedback (successes and failures in the course of the activity are apparent, so behavior can be adjusted as needed); balance between ability level and challenge (the activity is neither too easy nor too difficult); a sense of personal control over the situation or activity; and, the activity is intrinsically rewarding, so there is an effortlessness of action.

\subsection{Learning From Games}

Koster (2004) defines fun as "the feedback the brain gives us when we are absorbing patterns for learning purposes." Gee (2003) identified 36 learning principles embedded in good video games (such as Situated Meaning, Multiple 
Routes, Incremental Principle), which could be applied in educational settings. According to Prensky (2001), many of the elements that produce engagement in games could be employed also to make educational experiences more stimulating: interactivity, goals, outcomes and feedback, flow, win states, conflict-challenge, problem solving, social interaction, story. The affordances of games (action, structure, learning, creativity, social groups) and the affective states they produce (motivation, ego gratification, adrenaline, emotion) could be desirable features and outcomes also of a learning experience. Games can therefore be appropriate ways of achieving the entertainment goal in an edutainment experience : advocates of video games argue that games help developing abstract skills in probability, pattern recognition, and understanding causal relations (Johnson, S. 2005), have relevant learning principles embedded in their dynamics (Gee, 2003) and algorithmic understanding (Koster, 2004), offer opportunities to practice basic literacy skills (e.g. reading and writing) and learn valuable life lessons (Prensky, 2001). While the content of video games may be superficial, or even morally questionable, the underlying dynamics are extremely complex: game designers argue that players are not hooked by the game's "stage setting", but by its underlying logic (Koster, 2004). Through their compelling - when not addictive reward structure, games keep players engaged for hours in tasks that few would find agreeable, while requiring from them a good degree of complex reasoning (Johnson, S., 2005). For example, the "probing cycle" (players probe the virtual world, form a hypothesis, test it by probing the virtual world again, and refine it basing on the outcome) is the basic procedure of the scientific method.

Experiments with introducing commercial video games in school curricula have been tried. Playing Civilization III in classroom environments taught students that history, geography and politics are all interrelated - while also providing insights on different students' motivations. For example minority students, usually uninterested in history classes which they see as propaganda, got involved in the game when they realized that it allowed them to change history, and play e.g. as Native American tribes who resisted European colonists and retained their lands (Squire, 2005). Here, strong identity issues are at play.

Exploring hypothetical history also helps understanding why events unfolded the way they did. Multiplayer historical role-play games such as Revolution (a collaboration of MIT, Microsoft and Colonial Williamsburg Foundation) can help students understand the interplay between personal or local concerns and the national, public concerns taught in history classes (Squire and Jenkins, 2003).

Games to teach literary analysis are also being explored. Prospero's Island is a single-player, nonlinear, open-ended game on Shakespeare's Tempesta, developed by the Royal Shakespeare Company and MIT to help students understand the play through an immersive experience "inside" it (Squire \& Jenkins, 2003).

However, designing a multi-user game able to provide substantial learning as well as fun is a very hard task. An example is Arden, the World of William Shakespeare: while textually and historically accurate, full of Shakespearean quotes, characters and settings, it is not "gripping" as a game because "monsters were not part of the main game experience" (Castronova, 2007). The world failed to attract a sufficient number of players to allow using it for social science 
experiments, as originally intended. Online virtual worlds such as Second Life and role-play games with millions of players such as World of Warcraft are being used for testing social, politic, economic, even medical theories, e.g. the spreading of epidemic diseases (Johnson, 2007). However, such studies are hardly mainstream; there is also little research on how complex simulation games such as Sim City and Roller Coaster Tycoon could be used for learning (Squire, 2005).

Good video games are complex and very hard to beat: they require mastery of sophisticated worlds and often up to 50-100 hours to complete. Thus, they must be extremely good at teaching users how to play, through training modules, reward systems, and embedded dynamics encouraging exploration and experimentation. Games offer learning experiences that are embedded in action, experiential, multimodal; they involve discovery and self-knowledge; they situate meaning in embodied experiences and provide on-demand, just-in-time information (Gee, 2003). These are all desirable qualities for any educational intervention.

Given the enormous success of the videogames industry, with revenues larger than the GDP of a small country, a question emerges: is it possible to transfer the learning and motivational potential of entertainment into education (Barab et al., 2005), creating meaningful and engaging learning experiences?

\subsection{Games, Learning and Virtual Reality}

This section presents virtual reality applications involving elements of learning.

3D virtual environments hold great potential for creating experiences that are both engaging and educational. Yet this potential has just started being explored. Virtual reality has been used effectively in military or medical simulations of situations too dangerous, too expensive, or impossible to reproduce otherwise, e.g. for treating phobias or training firefighters. As for virtual environments used to teach curricular content, experiments include visualization and manipulation of complex, counter-intuitive concepts in scientific disciplines such as Physics (electromagnetic fields: Dede et al., 1997; visualization of molecular structures: Bergman et al., 2004; dynamics of flow lines: Bryson and Levit, 1992), Geometry (Cyber-Math: Naeve and Taxen, 2001) and Astronomy (Virtual Solar System Project: Hay et al., 2005). In some environments, users build rich, dynamic models of the phenomena studied, making theories explicit and developing a coherent understanding; in simulations they clarify misconceptions and construct a clearer understanding by manipulating variables and conducting systematic inquiry. 3D simulations have been used to build faithful virtual reproductions of ancient archaeological sites, such as ancient Olympia (Kenderdine, 2001); an ancient Greek house in Kassiopi (Mikropoulos and Strouboulis, 2004); or an architectural walkthrough of Monticello (Johnson, B., 2005). Second Life is being used by tourism and governmental agencies to attract interest on virtuallyreproduced historical sites (such as Chichen Itza in Mexico); also, universities and cultural institutions use it to host online courses and public events. Finally, virtual experiences have been designed to teach scientific research methods through situated learning (River City: Dede et al., 2005), social and environmental issues 
(Quest Atlantis: Barab et al., 2005; Virtual Gorilla Exhibit: Bowman et al., 1999), identity, personal and moral values (Zora: Bers, 2001). River City engaged over 1000 middle school students in observing problems, formulating and testing hypotheses, collecting data and deducing evidence-based conclusion while trying to solve the health problems of a 19th Century city (Dede et al., 2005). Quest Atlantis has been teaching thousands of elementary school children over the world about learning, playing and helping, encouraging them to take action in their local communities as part of the game (Barab et al., 2005).

This work examines another 3D-based edutainment experience, specifically addressing one of the most fascinating and challenging possibilities offered by the Web: cross-cultural interaction, the meeting of different cultural perspectives. In most educational virtual environments, content is mainly embedded in the 3D environment, and social interactions often play an accessory role. Little emphasis has been given to the potential educational value of cross-cultural interaction in virtual environments. The case study presented in this work, Learning@Europe (together with its "twin" Stori@Lombardia, their antecedent SEE - Shrine Educational Experience, and the new Learning@SocialSport) is to our knowledge the only example of a complex edutainment experience based on shared online 3D worlds that capitalizes on the different cultural backgrounds connected to the locations of participants, and uses their diversity as an asset to bring together and discuss multiple perspectives on a common cultural issue.

\section{Designing an Edutainment Experience}

Learning@Europe (L@E) targets high-school students aged between 14 and 19. Since 2004, it has involved over 6,130 students and teachers from 18 European countries and USA. L@E is a "blended" learning experience on European history, combining technology-based and "traditional" school activities. Students from four countries meet four times in a multi-user virtual environment, to play and learn under the guidance of two online tutors. Each synchronous session lasts about one hour. Between a session and the other, students interact with remote peers via online forums, study a set of interviews to renowned experts of history, and prepare research projects on their national identity and history, to compare with their remote peers. For details on the experience see (Di Blas \& Poggi, 2007, Paolini \& Di Blas, 2006).We highlight here the design elements crucial for engagement.

Interaction via chat with peers: during online sessions, students interact via chat both in the 3D world and in a parallel chat-only environment (dedicated to indepth cultural discussion, under the guidance of a human online moderator).

Olympic Games: in Session 1 students play ability games requiring mastery of movement in the 3D world, e.g. flying through circles (fig. 2); their team partners help increase the score by answering cultural quizzes in the chat.

Treasure Hunt: in Session 2 students must search objects in a labyrinth, select those related to a given cultural clue, and ask a team-mate to confirm their choice. 
Find your Way: in Session 3 two "blind" avatars must cross a path full of invisible obstacles, guided by their remote team-partners (who can see the obstacles). Correct answers to cultural questions in the chat facilitate the team mates' task (some obstacles become visible).

Questions via chat: the tutor in the 3D world asks quick factual questions on the contents showing visual aids (e.g. portraits of historical characters); the tutor in the chat-only environment asks conceptual questions requiring complex answers.

The main elements of fun in L@E, included for their motivational power, are the games (largely based on "physical' challenge, i.e. ability to control the avatar's movement), and the interaction with peers. The cultural questions, very important from an educational point of view, are also fun in that they are part of a "cultural" challenge: scores are awarded for the quickest correct answer. Tab. 2 relates these activities to the taxonomy of fun, also specifying their educational goal.

Table 2. Engaging activities in L@E according to the taxonomy of fun

\begin{tabular}{|c|c|c|}
\hline $\begin{array}{c}\text { Learning@Europe } \\
\text { activities }\end{array}$ & Elements from Taxonomy of Fun & Educational functions \\
\hline $\begin{array}{l}\text { Interaction via } \\
\text { chat with peers }\end{array}$ & $\begin{array}{l}\text { Fellowship. Some moments during the } \\
\text { sessions are especially dedicated to social } \\
\text { interaction (e.g. presentations of students' } \\
\text { classes and countries in the } 1^{\text {st }} \text { session) }\end{array}$ & $\begin{array}{l}\text { Increase of motivation. } \\
\text { Building social ties as a basis for } \\
\text { cross-cultural exchange. Practice } \\
\text { of English as a second language }\end{array}$ \\
\hline Olympic Games & $\begin{array}{l}\text { Challenge (ability to control the avatar's } \\
\text { movements, e.g. jumping, flying, steering; } \\
\text { also, race against time) } \\
\text { Ilinx (to some extent in the flying game) }\end{array}$ & $\begin{array}{l}\text { Increase of motivation } \\
\text { Development of skills for } \\
\text { advanced interaction with 3D } \\
\text { technology }\end{array}$ \\
\hline Treasure Hunt & $\begin{array}{l}\text { Challenge, "physical" and (mainly) } \\
\text { intellectual. Avatars must find and select } \\
\text { objects in a labyrinth basing on their } \\
\text { knowledge of the contents. Also, race } \\
\text { against time (and against the other team) } \\
\text { Discovery: players explore a labyrinth } \\
\text { Alea, in a small degree: finding objects in } \\
\text { the labyrinth (and the right objects first) } \\
\text { entails some luck. Yet, selecting correct } \\
\text { objects by guessing is discouraged. }\end{array}$ & $\begin{array}{l}\text { Increase of motivation } \\
\text { Application and reinforcement } \\
\text { of content-related knowledge } \\
\text { Building of collaboration skills } \\
\text { Development of skills for } \\
\text { advanced interaction with 3D } \\
\text { technology }\end{array}$ \\
\hline Find your Way & $\begin{array}{l}\text { Challenge, in terms of skilled control of } \\
\text { the avatar through a path with invisible } \\
\text { obstacles, and coordination with team } \\
\text { partners for directions; race with time. } \\
\text { An element of Fellowship is also present, } \\
\text { as teams collaborate with each other }\end{array}$ & $\begin{array}{l}\text { Increase of motivation } \\
\text { Building of collaboration skills } \\
\text { and team spirit } \\
\text { Development of skills for } \\
\text { advanced interaction with 3D } \\
\text { technology }\end{array}$ \\
\hline $\begin{array}{c}\text { Questions via } \\
\text { chat }\end{array}$ & $\begin{array}{l}\text { Challenge in cultural terms: participants } \\
\text { who first answer correctly gain scores. } \\
\text { Time is relevant in factual questions; } \\
\text { engagement is deeper in conceptual ones. } \\
\text { Storytelling in some sense: discourse on } \\
\text { history provides a "world" of characters, } \\
\text { places, and events far beyond the physical } \\
\text { and virtual spaces of participants }\end{array}$ & $\begin{array}{l}\text { Motivating the study of } \\
\text { contents } \\
\text { Cross-cultural discussion and } \\
\text { exchange of views on contents } \\
\text { Reinforcing relevant concepts } \\
\text { Testing knowledge of contents } \\
\text { Detecting misunderstandings } \\
\text { and knowledge gaps }\end{array}$ \\
\hline
\end{tabular}


A game must not necessarily include all the elements in the taxonomy in order to be entertaining; however, the presence of several elements can increase its appeal and extend it to a broader audience.

In the case of L@E, Challenge is present in both its "physical" and intellectual forms: controlling the avatar in the ability games and answering the cultural questions. This allows engaging both the "gamers" in the class (usually not the best students) and those more comfortable with "traditional" learning methods. Racing with time (playing or answering faster than others) increases engagement.

Fellowship is the other main entertaining aspect in L@E. Chatting with peers from different countries, playing in team with some and competing against others makes the experience more engaging. Interaction helps building social ties, critical for collaboration and cross-cultural exchange in cultural discussions, homework and team games. For non-native English speakers, social interaction is also a great incentive to English practice, an eye-opener on the importance of English, and a confidence-booster when students discover that they can understand each other.

The Narrative, Storytelling elements here are intended in a broader sense: while participants do not play any specific character, they discuss historical events which involve characters and stories, require some imagination, and provide a shared mental "world" beyond plain interaction with the 3D environment: while avatars seem just to be strolling around, students are actually constructing together an increasingly complex, detailed, and engaging picture of European history.

Sensation, Fantasy and Mimesis were not included in L@E because of flexibility and budget constraints: since each session involves a different set of countries, the virtual settings could not reproduce one specific place. Therefore the virtual environments resemble a content-neutral high-tech planet, with large round exhibit halls for discussions (Fig. 1) and ad-hoc environments for games (Fig. 2).

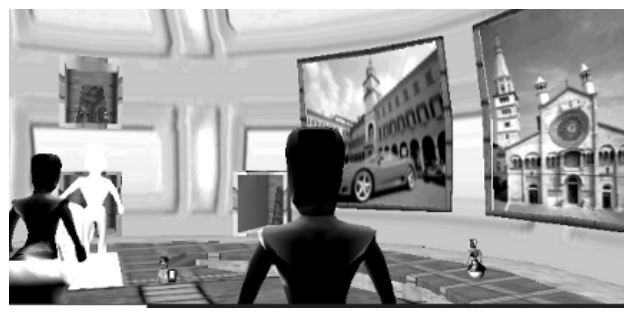

Figure 1. L@E: exhibit hall for presentations

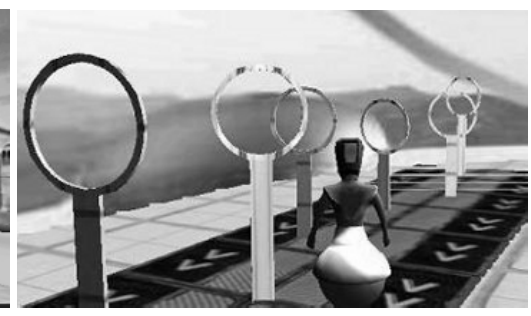

Figure 2. Space for the Olympic Games

Two other 3D-based projects with different requirements did include Mimesis elements: in SEE, students began their discovery of the Dead Sea Scrolls from the museum where the manuscripts are preserved (Fig. 3); in Stori@Lombardia, on the Middle Ages in Italy, virtual settings resembled a medieval castle (Fig. 4); research assignments often involved role-playing dramatic historical situations (e.g. the council of a city under siege) and enacting them in the final session. This included elements of Expression: the same theme assigned to different groups never produced the same results. Teachers reported extremely high engagement. 

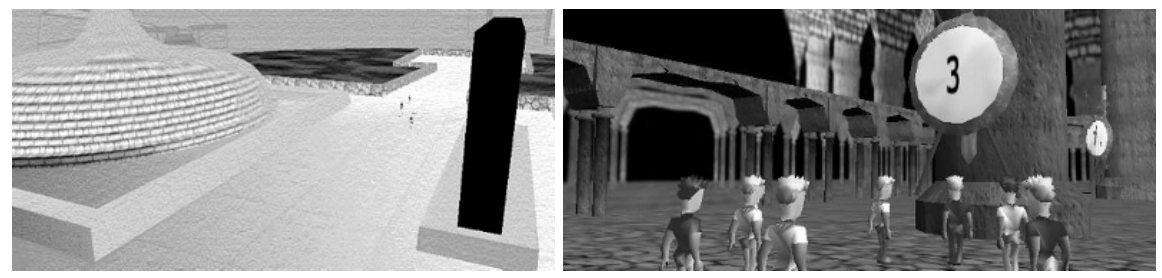

Figure 3. SEE: the virtual museum

Figure 4. The castle's dungeons in S@L

The design feature intended to generate Flow is the storyboard: the sequence of activities to take place during online meetings; it is carefully planned in order to never leave the students without something to do or a goal to achieve.

The Alea aspect has not been included in the design of any of the activities, except to a small degree in the Treasure Hunt, where participants may complete their hunt faster if the first objects they come across are the correct ones. Students who try answering cultural quizzes by guessing, however, are penalized.

A slight element of Ilinx might be present in the Olympic Game that requires flight (Fig. 2); however, movement in the 3D environment is not as life-like as in fly-training simulations. The fun factor here is mainly the "physical" challenge of controlling the avatar's movements, with an element of Mimesis in the excitement of a situation that has no counterpart in real life.

\section{Investigating Fun Through Empirical Evidence}

This section presents empirical evidence for the level of engagement achieved in the last two editions of Learning@Europe, investigating the reasons behind it as well as measuring the educational impact of the experience.

Learning@Europe involved between November 2004 and February 2008 over 6,130 students and more than 350 teachers from almost 190 schools in 19 countries. The other edutainment experiences based on a similar sequence of activities in shared 3D environments, i.e. Shrine Educational Experience (SEE), Stori@Lombardia (S@L) and Learning@SocialSports (L@SS), involved since 2002 another 3000 teenage participants from Italy, Belgium and Israel.

All experiences were monitored using similar sets of online surveys to teachers after every synchronous online meeting and to students before and after the experience. Online tutors wrote a report after every session. Chat transcripts, forum posts and students' works were collected and analyzed. A few on-field observations were conducted in some schools (at least 20 hours of class interaction have been video-taped). Focus groups with teachers were held in the early stages of each project and after deployment to assess the reliability of survey data.

While data from all projects through six years consistently show satisfactory results in terms of students' engagement and learning, we discuss here only the last two years of L@E, since other data are less comparable in terms of survey 
questions and rating scales. Approximately 1000 students and 100 teachers took part in L@E 2006-07, whereas L@E 2007-08 - the first experiment involving also an American school - involved 130 students and 8 teachers. Survey responses represent approximately $45-55 \%$ of students and $65-90 \%$ of teachers. To increase reliability, when possible we triangulated findings from multiple sources (teachers, students, online tutors), integrating quantitative data with qualitative evidence from open-ended survey questions, tutors' reports, etc.

\subsection{Are L@E Activities Engaging?}

Learning@Europe online activities involve classes of 15-25 students, of which only 4 at a time directly control a virtual user. Only $50-60 \%$ of survey respondents ever get to move an avatar in the 3D world or write in the chat, and less than $40 \%$ play a game: while they often take turns at the computers, in 70-80\% of classes the most skilled are chosen to play the games. Most students spend the sessions grouped around their classmates, suggesting the next move or answer, with almost half of them never even touching the keyboard: yet, bored or slightly bored students are hardly ever more than $13 \%$, while those rating an activity "really exciting!" (5 points out of 5) are around $20 \%$.

In the surveys, 541 students in L@E 2006-07 and 57 students in L@E 2007-08 rated their engagement in L @ E activities on a 5-points scale (1=boring, 3=quite interesting, $5=$ really exciting!). The highest average rating is for interaction with foreign peers ( 3.85 out of 5), immediately followed by the L@E experience as a whole (3.82): $30 \%$ of students found it "quite interesting" and 65\% rated it "engaging" or "really exciting!". They appreciated the possibility to work in group with classmates (3.66), and enjoyed the questions via chat (3.58) even more than the games (3.5). Even "traditional" activities such as studying interviews (3.12) and preparing homework (3.19) excited some interest.

72 teachers over the two years also rated their students' engagement in online and class-based activities on a 5-points scale ( $1=$ not involved at all, $3=$ acceptable involvement, $5=$ enthusiastic involvement). Again, questions and discussions via chat (4.42 out of 5) score slightly higher than the games (4.36). Discussing the interviews (3.59) and doing the assignment (3.57) seem more engaging than studying the materials (3.47) and the forums (3.34), which few students used.

Asked to compare their students' engagement in L@E versus usual school activities, most teachers replied that it was equal and often superior in L@E: "The involvement in the project looks really special and enthusiastic", was the comment of a teacher. Others noted that the experience captured the interest of those usually not among the most involved: "I could see that the more 'scholars' may not be the ones who are most at ease, on the contrary some find a field where to express themselves." Teachers, tutors and observers in schools agree that a sense of Flow was perceivable during most sessions. 78.9\% of students in L@E 2006-07 $(\mathrm{N}=518)$ and $78.2 \%$ in $\mathrm{L} @ \mathrm{E} 2007-08(\mathrm{~N}=55)$ declared they were so involved in the sessions that they lost track of time. 


\subsection{What Creates Engagement in L@E?}

We now investigate the reasons behind engagement. Students were asked to select the session they liked best and give up to 3 reasons why they enjoyed it most (Fig. 5). The element selected by the largest number of students, "meeting new people", is Fellowship in the taxonomy of fun. While Challenge is the next preferred component, it seems that students enjoyed the overall competition, the cultural questions and the novelty of the experience more than the games.

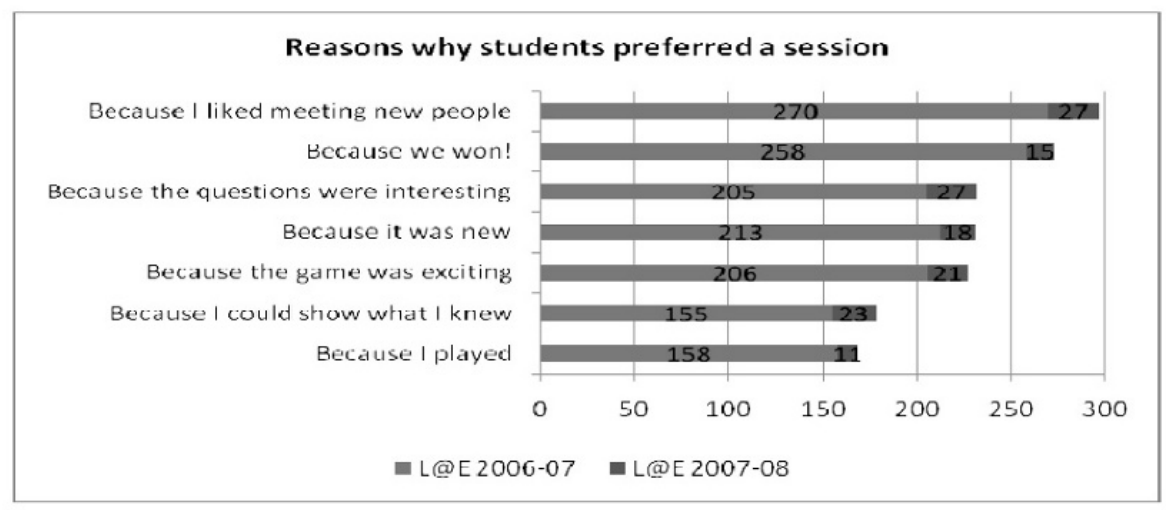

Figure 5. Preferences of students choosing max. 3 reasons why they enjoyed a session best. 539 respondents for L@E 2006-07 and 57 respondents for L@E 2007-08.

Students were also asked to rate the most attractive aspect of L@E on a 5points scale ( $1=\mathrm{I}$ didn't like it at all, 3=I liked it, 5=It was great!!). What they appreciated most was "doing something different from usual school activities" (4.06 out of 5, N=595): L@E appears as a welcome interruption of school routine. Immediately following came Fellowship: "meeting foreign students" (3.91) and then "studying history in a new way" (3.73). Challenge - "games and competition at school" - is rated the same as "studying with the computer": 3.58 .

In conclusion, Learning@Europe is able to engage participants actively, even enthusiastically, through its novelty in school contexts, Fellowship and Challenge.

\subsection{Is it Just Fun, or Are Students Also Learning?}

We presents here also some evidence of Learning@Europe's educational impact. The students' engagement and fun were not achieved at the expense of their learning: on the contrary they have very likely enhanced it.

72 teachers over the two years rated the educational effectiveness of L@E activities on a 5-points scale (1=very poor, 3=good, 5=excellent). The most learning-effective activities are also the most engaging ones: the cultural challenge via chat (average rating: 3.76 out of 5) and the interaction and games in the $3 \mathrm{D}$ 
world (3.74). "Proper" learning activities, namely preparing homework (3.70) and studying the interviews (3.66), were rated slightly lower; they involved respectively $40-50 \%$ and $70-78 \%$ of participants, but - unlike chat and games could not be followed by the rest of the class through a projection screen.

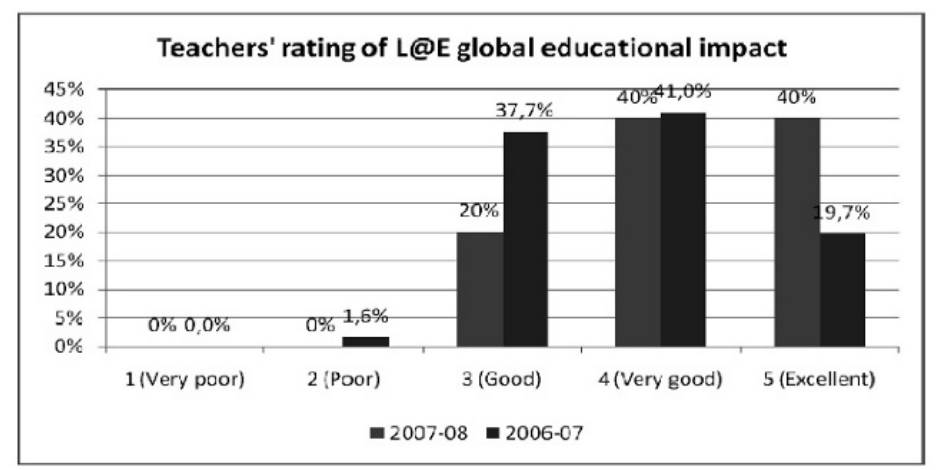

Figure 6. Ratings by 61 teachers from L@E 2006-07 and 5 teachers from L@E 2007-08

As shown in Fig. 6, almost the totality of teachers is satisfied with the educational impact of the L@E experience, and 60 to $80 \%$ are extremely satisfied. Teachers have different opinions on the educational effectiveness of individual activities: a class may benefit more from some and put less effort in others. Yet, all agree that the experience as a whole was beneficial in a variety of ways: students' improvements in terms of knowledge and understanding of history were rated high or very high by $35-50 \%$ of teachers, and good by $40-45 \%$. Students practiced English as a second language, developed technological skills, skills for group work and new learning methods. The experience also changed their attitude towards foreign cultures, history, and school: $30-50 \%$ of teachers reported major or excellent improvements, and 40-50\% good improvements. No teacher reported "no improvement at all" in any of the above areas.

\section{Conclusions}

Evaluation data from Learning@Europe (and related projects) shows that 3D world-based edutainment experiences can be educational and fun at the same time. The primary strategies to create engagement are Fellowship and Challenge, both in intellectual and "physical" form. Many elements in the experience design also favor Flow (Csikszentmihalyi, 1991).

Fellowship - interaction with remote peers and classmates - is an extremely powerful source of engagement for young users. Occasions should be created to encourage social interaction, which is also crucial in creating a solid basis for collaborative activities and cross-cultural exchange. 
Challenge can be both "physical", based on skilled control of the avatar, and "cultural": quizzes and riddles, often even more engaging. In our programs, participants learn about the subject by reading a common set of materials before meetings: this puts all on equal footing for the cultural challenge; human online tutors acting as discussion moderators of and referees of games provide immediate feedback, adjusted to the quality of responses. Challenges must be adequate to the participants' abilities: neither too easy, nor too hard. Cycles of evaluation and refinement over years allowed us to find a balance: games were redesigned based on participants' feedback, ambiguous questions were revised, a simplified version of contents was created for younger students. Also, rules must be clear from the beginning and scores based on unambiguous criteria.

Educational effectiveness is based on the reading of quality educational material, providing a common ground for content-based interactions. Competition and interaction provide the motivation for studying; discussions with peers from different backgrounds make different perspectives emerge, challenge the interpretations of individual students, and force them to rethink critically at what they learned, reorganizing knowledge in a more complete picture. Assignments offer occasions for in-depth reasoning and research between online meetings.

Readings, assignments, online attendance at scheduled times are demanding tasks possible in the "captive" situation of formal school environments, where the alternative is another - often less attractive - mandatory activity: as a US students pointed out when asked what he expected from L@E, "I'm not exactly sure, but it beats going through the same notions throughout an entire semester." The motivation of the teacher is extremely important: if teachers shows no interest in the program, students will hardly bother doing the required activities.

To favor a situation of Flow, the sequence of activities is defined in advance and the tutor is quick in setting a new goal once an activity is completed. This is especially important when collaborative time online is limited.

Educational benefits go far beyond the knowledge of the subject matter: collateral benefits, including development of technological, social, language and communication skills, ability to work in groups, discovery of new learning methods, attitude change, motivation and engagement, should also be considered: it is extremely unusual for a single educational activity to offer such a wide range of valuable educational benefits all at the same time. Opportunities for the professional development of instructors should also be considered.

\section{References}

Barab, S., Thomas, M., Dodge, T., Carteaux, R., and Tuzun, H.: Making learning fun: Quest Atlantis, a game without guns. Educational Technology R\&D, 53(1), 86-107 (2005).

Bartle, R.: Hearts, Clubs, Diamonds, Spades: Players who suit MUDs. J. of MUD Research, 1(1) (1996). http://www.brandeis.edu/pubs/jove/HTML/v1/bartle.html. Accessed 11 Apr 2008.

Bergman, L., Richardson, J., Richardson, D., and Brooks, F.: View: an exploratory molecular visualization system with user-definable interaction sequences. Computer Graphics - Proc. SIGGRAPH 2004, 117-126 (2004). 
Bers, M.U.: Identity Construction Environments: Developing Personal and Moral Values Through the Design of a Virtual City. J. of the Learning Sciences, 10(4), 365-415 (2001).

Bowman, D., Wineman, J., Hodges, L., and Allison, D.: The Educational Value of an Information-Rich Virtual Environment. Presence: Teleoperators and Virtual Environments, 8(7), 317-331 (1999).

Bryson, S. and Levit, C.: The Virtual Wind Tunnel. IEEE Computer Graphics and Applications, 12(4), 25-34 (1992).

Caillois, R.: Man, play and games. Free Press, New York (1961).

Castronova, E.: Two Releases: Arden I and Exodus. Terra Nova. 27 November 2007. Available at http://terranova.blogs.com/terra_nova/2007/11/two-releases-ar.html. Accessed 9 Apr 2008.

Csikszentmihalyi, M.: Flow: The Psychology of Optimal Experience. Harper Perennial, New York (1991).

Dede, C., Clarke, J., Ketelhut, D., Nelson, B., and Bowman, C.: Students' Motivation and Learning of Science in a Multi-User Virtual Environment. Presented at AERA 2005. Available:http://muve.gse.harvard.edu/muvees2003/documents/Dede_Games_Symposium_A ERA_2005.pdf. Accessed 10 Feb 2008.

Di Blas, N., and Poggi, C.: European Virtual Classrooms: how to build effective 'virtual' educational experiences. Virtual Reality: Special Issue on Virtual Reality in the e-Society. Springer, London. http://www.springerlink.com/content/r264167mt8654q81 Accessed Feb 08

Gee, J.P.: What Video Games Have to Teach Us About Learning and Literacy. Palgrave, New York (2003).

Hay, K.E., Kim, B., and Roy, T.C.: Design-Based Research: More than Formative Assessment? An Account on the Virtual Solar System Project. Educational Technology, 45(1), 34-41 (2005).

Huizinga, J.: Homo Ludens: A Study of the Play Element in Culture. Beacon Press, Boston (1938)

Hunicke, R., LeBlanc, M., and Zubek, R.: MDA: A Formal Approach to Game Design and Game Research. Proc. of the Challenges in Game AI Workshop, 19th National Conference on Artificial Intelligence (2004).

Johnson, B.: Place-Based Storytelling Tools: A New Look at Monticello. Proc. Museums and the Web 2005. Archives and Museums Informatics, Toronto (2005).

Johnson, C.Y. Online gamers become guinea pigs. Epidemics uncorked in virtual worlds. The Boston Globe, 25 Aug. 2007. Available: http://www.boston.com/business/technology/ articles/2007/08/25/online_gamers_become_guinea_pigs/. Accessed 11 Apr 2008.

Johnson, S.: Everything Bad is Good for You. How Today's Popular Culture is Actually Making Us Smarter. Riverhead Books, New York (2005).

Kenderdine, S.: 1000 Years of the Olympic Games: Treasures of Ancient Greece. Proc. Museums and the Web 2001. Archives and Museum Informatics, Pittsburgh (2001).

Koster, R.: A Theory of Fun for Game Design. Paraglyph Press, Scottsdale (2004).

Mikropoulos, T. A., and Strouboulis, V.: Factors that influence presence in educational virtual environments. Cyberpsychology and Behavior, 7(5), 582-591 (2004).

Naeve, A., and Taxen, G.: CyberMath: Exploring Open Issues in VR-Based Education. Proc. SIGGRAPH 2001, Educators Program, 49-51 (2001).

Paolini, P., and Di Blas, N.: Multi-User Virtual Environments for Education: A European Experience. Proc. E-Learn 2006, AACE Press, 1383-1394 (2006).

Prensky, M.: Digital Game-Based Learning. McGraw-Hill, New York (2001).

Squire, K.: Resuscitating research in educational technology: Using game-based learning research as a lens for looking at design-based research. Educational Technology, 45(1), 8-14 (2005).

Squire, K., and Jenkins, H.: Harnessing the power of games in education. InSight, Vol.3, 5-33 (2003). http://website.education.wisc.edu/kdsquire/manuscripts/insight.pdf. Accessed $11 \mathrm{Apr}$ 2008. 